\title{
Estimation of interstory drift ratio and performance levels for the multistory buildings considering the effect of soil-structure interaction
}

\author{
Yapı-Zemin etkileşimi etkisine bağlı olarak çok katlı binalarda göreli kat \\ ötelemesi oranının ve performans seviyesinin belirlenmesi
}

\author{
Ayşe Elif ÖZSOY ÖZBAY* ${ }^{*}$ iD Pelin GÜNDES BAKIR ${ }^{2}$ iD \\ 1Department of Civil Engineering, Faculty of Engineering and Natural Sciences, Maltepe University, İstanbul, Turkey. \\ elifozsoy4@gmail.com \\ 2Department of Civil Engineering, Faculty of Civil Engineering, İstanbul Technical University, İstanbul, Turkey. \\ gundesbakir@gmail.com
}

\begin{abstract}
The interaction of soil and structure significantly alters displacement response of the framed structures. This effect is mostly important for the buildings resting on soft soils. Including these effects in the dynamic analysis, the lateral displacements and the drift demand of the building increase depending on the type of the underlying soil. The variation in the drift demand due to the interaction effects also changes the performance level of the structure, as well. Since the interstory drift ratio is one of the most important demand parameter, it is essential to integrate the effects of soil structure interaction within the structural design process and the performance assessment. In this study, the drift demand of an existing multistory building is obtained using an improved technique for dynamic analysis of the soil-structure systems. The technique is based on the analysis of the multistory buildings under the seismic wave propagation employing Finite Element Methods (FE) for the superstructure and Boundary Element Methods (BE) for the underlying soil medium. The lateral displacement response at each story level is used to determine maximum interstory drift ratio of the building and to estimate structural performance level.
\end{abstract}

Keywords: Soil-Structure interaction, Finite elements method, Seismic wave propagation.

\section{Introduction}

Recent studies in earthquake engineering reveal that earthquake resistant design of structures requires more accurate estimation of seismic demands of structures [1]. The drift is a fundamental seismic demand parameter that is used to assess the performance level and to quantify the structural damage in performance based design. The current seismic design codes define ranges of allowable drift limits for each building performance level. Thus, great effort is needed to estimate the drift demand including the higher order mode shapes of the structures. There is a need for reliable tools to obtain the structural response representing the overall behavior of the soil-structure system and to estimate the performance level more accurately. Soil-structure interaction (SSI) especially changes the displacement response as well as the dynamic characteristics of a structure.
Öz

Yapı-zemin etkileșimi, çerçeve sistemli yapıların deprem yükü altındaki yerdeğiștirme cevabını önemli ölçüde değisştirmektedir. Bu etki özellikle yumuşak zemin üzerine inşaa edilmiş yapılarda çok daha önemlidir. Dinamik çözümlemede bu etki göz önüne alındığı takdirde; yapının inşaa edildiği zemin türüne bağlı olarak yanal yerdeğiștirmelerinde ve kat ötelemesi talebinde artıs meydana gelebilir. Etkileșime bağlı olarak yapının kat ötelemesi talebinde meydana gelen farklılık, aynı zamanda yapının performans seviyesini de değiştirir. Göreli kat ötelemesi oranı, deprem etkisi altında tasarım sürecindeki en önemli yapısal parametrelerden birisidir. Bu sebeple, yapı-zemin etkileșimi etkilerinin yapısal tasarım aşamasında ve performansın belirlenmesinde dikkate alınması oldukça önemlidir. Bu çalışmada, mevcut çok katlı bir yapının kat ötelemesi talebi, yapı-zemin sistemlerinin dinamik çözümlemesi için geliştirilmiş olan sayısal bir yöntem ile elde edilmiştir. Bu yöntemde, çok katlı yapıların deprem dalgaları etkisi altındaki dinamik cevabinın çözümlenmesinde üstyapının sayısal modeli için Sonlu Elemanlar Yöntemi; zemin için ise Sınır Elemanlar Yöntemi kullanılmıştır. Kat seviyelerinde hesaplanan yanal yerdeğiștirme değerleri kullanılarak mevcut bir yapıda maksimum göreli kat ötelemesi oranı ve yapısal performans düzeyi belirlenmiștir.

Anahtar kelimeler: Yapı-Zemin etkileșimi, Sonlu elemanlar yöntemi, Deprem dalgası hareketi.
In this study, a procedure that obtains the drift demand of multistory buildings considering the effect of SSI is proposed. The interstory drift ratio (IDR) at each story level due to seismic wave motion is obtained through dynamic analysis of soilstructure system. Underlying soil type can greatly alter the displacement response compared with the fixed based structure. Including the effect of SSI, the improved technique permits more reliable estimation of the drift demand, hence it provides a more realistic assessment of the building performance level.

Miranda et al. [2] mentioned that IDR is the response parameter which is closely related with structural damage referring to the previous studies conducted on the drift and the earthquake resistant design [3]-[6]. The drift spectrum developed by Iwan [7] is based on a continuous shear beam model including the effect of higher modes on the drift demands. It provides a better estimation of maximum interstory demands in comparison with those obtained by the response spectrum, since the

${ }^{*}$ Corresponding author/Yazışılan Yazar 
response spectrum is based on a single-degree-of freedom system. Miranda et al. [2] have developed an extended drift spectrum for the buildings using a continuous model which is a combination of a flexural beam and a shear beam. Apart from the beam analogies for the drift spectrum cited above, Akkar et al. [1] have modified the drift expression employing beam-to column stiffness ratio which represents the behavior of the moment resisting frames. The drift values are generally used in the preliminary design or rapid assessment of the buildings. However, none of the drift spectrum models include the effect of SSI. Thus, they are inadequate to reveal the real building performance level.

SSI causes changes in the modal parameters of the structures [8]-[11]. The displacement response is affected by the soil type under the structure as well as the fundamental frequency of the structure. The seismic waves that propagate through the different soil layers with varying mechanical characteristics, cause variations in base excitation as they reach the base of a structure. Thus, the soil conditions change the displacement response as well as the fundamental frequency of the soilstructure system.

Previous studies on the numerical modelling of the soilstructure systems have been conducted in the literature [12]-[15]. Most of the techniques are based on the coupled BEM-FEM approach employing the Green's functions for the soil medium and the fundamental solutions of the wave propagation [16]-[18]. Dendrou [19] introduced a method for dynamic analysis of soil-structure systems under wave propagation. In this study, the structure has been modeled by the Finite Elements (FE) and the soil has been represented by the Boundary Elements (BE) methods. The coupling of the models is accomplished at the soil-structure interaction surface using the substructure approach.

Substructure method enables the use of different methods for modeling the superstructure and the soil, separately. The method provides the coupling of the two separate models at the soil-structure interaction surface. Employing the substructure method, the numerical modeling of two substructures can be conducted considering the nonlinear behavior of the soil or the structure, as well [20]. In a recent study, the load distribution for capped pile and piled rafts in homogeneous layered soils was examined. The substructure method was used to develop 3D FEM-BEM based models in order to investigate the vertical and lateral dynamic response of piled raft systems for various soil profiles. It was observed that dynamic load distribution between pile and raft for $2 \times 2$ piled rafts, was frequency dependent in the vertical mode and frequency independent in the lateral mode [21]. In another study, the effect of SSI and spatial variations in ground motion were investigated for cablestayed bridges. Through the use of substructure method, the soil-structure problem was favorably encountered by incorporation of uniform isotropic viscoelastic half-space approach for soil and the nonlinear behavior of the bridge system [22].

In this study, the maximum horizontal response amplitude occurring at the story levels of multistory buildings is utilized to obtain the interstory drift ratio. Subsequently, the IDR values are employed to estimate the building performance level that is defined by the seismic codes. The dynamic response of an existing multistory building under the seismic wave motion is obtained by the numerical technique that is developed for the structures having surface foundations [23].
The numerical technique is based on the Substructure Method which has been used for the coupling of the two models representing the structure and the soil. The unbounded soil medium has been modeled by the Boundary Element Method (BEM) considering the soil as an elastic isotropic and homogeneous half space, whereas the three dimensional (3D) Finite Element Model (FEM) of the building was performed to obtain structural response. The coupling of the two separate systems has been accomplished at the interface region utilizing the displacement continuity equations of the soil-structure system. Apart from the methodology developed by Dendrou [19], the new method suggests an effective numerical technique for the soil-structure systems with more accurate displacement response modifying the dynamic transformation matrix to include the effect of damping.

In the improved formulation, the Green's functions are used to formulate the soil as an elastic half-space. Structural modelling is accomplished by Finite Element Code, ANSYS [24]. Employing the sparse matrix techniques, a fast solution technique is proposed in order to combine the soil medium with the structural model [25].

\section{Numerical modeling of the soil}

The soil medium has been represented by the incident shearhorizontal (SH) and shear-vertical (SV) wave motions and the impedance matrix of the soil. The motion induced by seismic waves is determined at the interface nodes between the structure and the soil using the elastic wave theory. Finally, the free-field displacement vector due the incident wave motion is transformed into the coordinates of the structure by the angle between vertical planes of the wave motion and the structure (Figure 1) [19],[26].

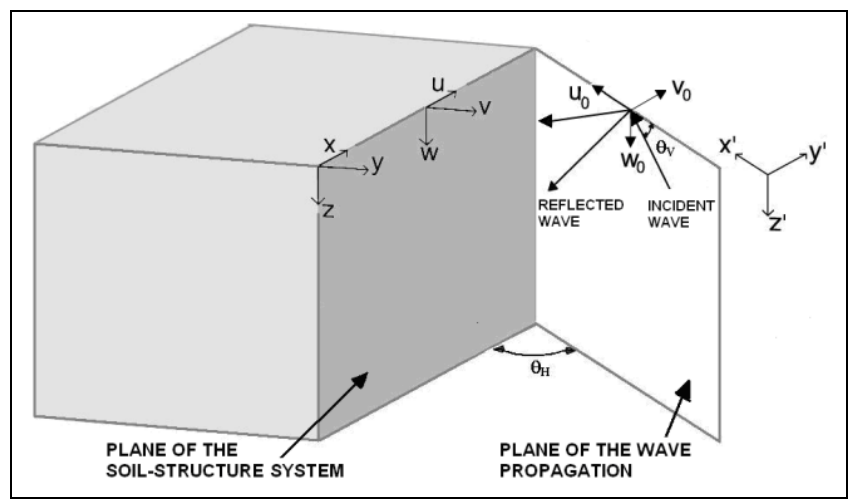

Figure 1. Transformation of the seismic wave displacement vector into the plane of the structure.

The impedance matrix referring to the soil medium is calculated using the frequency-dependent Green's Functions that define the relationship between a unit harmonic force applied on the elastic half space and the displacement caused by the harmonic excitation at the surface [27]-[28]. The displacement due to the harmonic force applied on a surface point of the halfspace is defined by the Green's functions matrix as:

$$
\{u(x)\}=\left\{\begin{array}{l}
u_{1} \\
u_{2} \\
u_{3}
\end{array}\right\} \cdot e^{i \omega t}=\left[G\left(\omega,\left(x-x_{0}\right)\right)\right] \cdot\left\{P\left(\left(x_{0}\right)\right\}\right.
$$

$x$ and $x_{0}$ are the coordinate vectors of interface nodes where the displacement is calculated and the harmonic force is applied, respectively. $\left\{P\left(\left(x_{0}\right)\right\}\right.$ is the harmonic force applied at 
$x_{0}$ with the excitation frequency of $\omega$. In Cartesian coordinates, the Green's functions matrix is expressed as:

$$
=\frac{1}{\mu R}\left[\begin{array}{ccc}
{\left[G\left(\omega,\left(x-x_{0}\right)\right)\right]} \\
f_{r r} \cos ^{2} \theta-f_{\theta r} \sin ^{2} \theta & \left(f_{r r}+f_{\theta r}\right) \cos \theta \sin \theta & f_{r z} \cos \theta \\
\left(f_{r r}+f_{\theta r}\right) \cos \theta \sin \theta & f_{r r} \sin ^{2} \theta-f_{\theta r} \cos ^{2} \theta & f_{r z} \sin \theta \\
-f_{r z} \cos & -f_{r z} \sin \theta & f_{z z}
\end{array}\right]
$$

Where $\mu$ refers to the soil shear modulus; $R$ is the distance between the application point of the force and the observer point; $\theta$ is the angle between the distance $R$ and $\mathrm{x}$ axis (Figure 1); $f_{r r}, f_{\theta r}, f_{r z}$ and $f_{z z}$ are the components of Green's functions in cylindrical coordinates (Appendix A) [26]. The raft foundation of the structure is idealized with the mesh of rectangular elements at the interface [19]. Assuming that stress is constant over the interaction surface, Eq. (1) yields the nodal displacement vector at the interface as:

$$
u=C_{S} \cdot P
$$

Where $C_{S}$ is the compliance matrix of the elastic halfspace and $P$ is the force vector defined at the interface nodes. The compliance matrix of the half-space obtained as:

$$
C_{S}=\varphi \cdot A^{-1} \cdot T
$$

Where $T$ is the transformation matrix of the force vector, $A$ is the diagonal matrix which contains the area of the rectangular elements. Each entry of the matrix, $\varphi$ is obtained integrating the Green's functions matrix over the interaction surface as;

$$
\varphi\left(x_{i}, x_{j}\right)=\left[\iint_{A} G\left(\omega,\left(x_{i}-x_{j}\right)\right) \cdot d S_{j}\right]
$$

Where $x_{i}$ and $x_{j}$ are the position vectors of two interface nodes [19]. Finally, the excitation force vector, $P_{S}$ induced by SH or SV waves at the interface nodes is obtained as:

$$
P_{S}=K_{S} \cdot u_{f f}
$$

Where $K_{S}$ is the impedance matrix (inverse matrix of $C_{S}$ ) and $u_{f f}$ is the wave displacement vector.

\section{Derivation of the numerical methodology using the substructure method}

The separation of the structure and the soil medium enables the modeling of the two parts with different methods. Thus, FEM of the structure and the soil medium defined by an elastic homogeneous half space are coupled along the interaction surface conforming the compatibility equations and the dynamic equilibrium. Using substructure method, the set of dynamic equilibrium equations of the soil-structure system is derived in matrix form as:

$$
\begin{aligned}
{\left[\begin{array}{cc}
M_{11} & 0 \\
0 & M_{22}
\end{array}\right]\left\{\begin{array}{l}
\ddot{y}_{1} \\
\ddot{y}_{2}
\end{array}\right\}+} & {\left[\begin{array}{cc}
C_{11} & 0 \\
0 & 0
\end{array}\right]\left\{\begin{array}{l}
\dot{y}_{1} \\
\dot{y}_{2}
\end{array}\right\}+\left[\begin{array}{ll}
K_{11} & K_{12} \\
K_{12}^{T} & K_{22}
\end{array}\right]\left\{\begin{array}{l}
y_{1} \\
y_{2}
\end{array}\right\} } \\
& =\left\{\begin{array}{c}
0 \\
P_{2}
\end{array}\right\}
\end{aligned}
$$

Where $M_{11}$ and $M_{22}$ are the mass matrices of the structure and interaction surface; $C_{11}$ is the diagonal damping matrix for the structure; $K_{11}$ and $K_{22}$ are the stiffness matrices of the structure and the base nodes; $K_{12}$ is the coupled stiffness matrix of structure and interaction surface; $P_{2}$ refers to the base force vector; $y_{1}$ and $y_{2}$ are the time-dependent displacement vectors of the structure and the base nodes. The structural response, $y_{1}$ is composed of the static and the dynamic displacement vectors as:

$$
y_{1}=y_{1 S}+y_{1 D}
$$

Using Eq. (8) and the first row of the dynamic equilibrium equation matrix given in Eq. (7), $y_{1}$ is expressed by the response of the interface nodes, $y_{2}$ as:

$$
y_{1}=\left[R_{S}+R_{D}\right] \cdot y_{2}
$$

Where $R_{S}$ and $R_{D}$ are the static and the dynamic transformation matrices of the combined soil-structure system. Static transformation matrix is defined by the product of the stiffness matrices as:

$$
R_{S}=-K_{11}^{-1} \cdot K_{12}
$$

In the study conducted by Dendrou [19], the dynamic transformation matrix, $R_{D}$ has been defined in terms of the static transformation matrix, $R_{S}$. Substituting Eq. (8) into the first row of the dynamic equilibrium equation matrix in Eq. (7), $R_{D}$ has been derived as:

$$
R_{D}=\Omega^{2} \Phi . S^{-1} . \Gamma
$$

Where $\Phi$ is the modal matrix normalized with the mass matrix of the structure $M_{11}, \Omega$ is the wave excitation frequency and $\Gamma$ is the modal participation factor matrix obtained as:

$$
\Gamma=\Phi^{T} \cdot M_{11} \cdot R_{S}
$$

The frequency-dependent $\mathrm{S}$ matrix is calculated as:

$$
\mathrm{S}=-\left[\Omega^{2}\right]+\mathrm{i}\left[2 \Omega \omega_{N} \xi_{N}\right]+\left[\omega_{N}^{2}\right]
$$

Where $\left[\omega_{N}^{2}\right]$ and $\left[\Omega^{2}\right]$ are the diagonal matrices of the structure's $\mathrm{n}^{\text {th }}$ natural frequency and the wave excitation frequency, respectively.

The proposed matrix for dynamic transformation, $R_{D}$ introduced in this study includes the effect of damping of the structure, suggesting a better estimation of the displacement response of the soil-structure system [23]. Using the orthogonality of the modal vectors according to the stiffness and mass matrices, the dynamic transformation matrix, $R_{D}$ has been redefined as:

$$
R_{D}=\Omega^{2} \Phi . S^{-1} \cdot \Gamma-\mathrm{i} \Omega \Phi . S^{-1} \cdot\left[2 \omega_{N} \xi_{N}\right] . \Phi^{T} M_{11} R_{S}
$$

Where $\left[2 \omega_{N} \xi_{N}\right]$ is the diagonal matrix consisting of the $\mathrm{n}^{\text {th }}$ natural frequency and the modal damping ratio proportional to mass and stiffness matrices of the structure. Considering harmonic displacement and excitation force along the interface as $y_{2}=\left\{y_{20}\right\} e^{i \Omega t}$ and $P_{2}=\left\{P_{20}\right\} e^{i \Omega t}$, the displacement response amplitude vector for interface nodes, $y_{20}$ is determined by the second row of the dynamic equilibrium equation matrix in Eq. (7). Substituting Eq. (9) into the second row of the matrix for equations of motion in Eq. (7), the effective impedance matrix of the structure, $K_{S T}$ can be obtained as:

$$
K_{S T}=-\Omega^{2} \mathrm{M}_{22}+K_{12}^{T} \cdot\left[R_{S}+R_{D}\right]+K_{22}
$$

Which describes the relation between the displacement amplitude vector, $y_{20}$ and the excitation force vector $P_{20}$ along the interface. Dendrou [19] expressed the force vector along the 
interface, $P_{2}$ as the sum of the excitation force vector, $P_{\mathrm{S}}$ induced by the incident SH or SV wave as $P_{S}=K_{S}$. $u_{f f}$ and the resisting forces defined as $P_{R}=-K_{S} \cdot y_{2}$ which is given below:

$$
P_{2}=P_{20} \cdot e^{i \Omega t}=\left[P_{S}+P_{R}\right] \cdot e^{i \Omega t}
$$

Using Eq. (15) and (16), the response vector along the interface $y_{2}$ is obtained as:

$$
y_{2}=\left[K_{S T}+K_{S}\right]^{-1} \cdot P_{S}
$$

Using Eq. (9), the response of the structure is finally determined as:

$$
y_{1}=\left[R_{S}+R_{D}\right] \cdot\left[K_{S T}+K_{S}\right]^{-1} \cdot P_{S}
$$

\section{Case 1: Single story 3D frame-validation of the coupled frequency with the equivalent models}

The dynamic analysis of a single story 3D frame is conducted to verify the proposed numerical methodology. The single span frame consists of a raft foundation resting on stiff clay, the floor slab represented by a shell element; four beams and four columns (Figure 2). The soil-structure system is analyzed for a vertical SH wave excitation with the amplitude of $2 \mathrm{~A}_{0}=2 \mathrm{~cm}$ in $x$ direction (Table 1). In order to validate the proposed procedure, the variations in the fundamental frequency of the soil-structure system including the effect of SSI obtained by the proposed procedure is compared with the results calculated by the formulations recommended by FEMA 450 [29] and the equivalent single degree of freedom (SDOF) model for soilstructure systems [30] in the following sections.

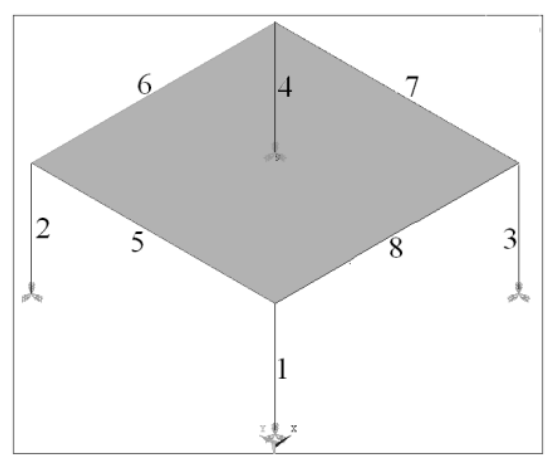

Figure 2. 3D modelling of the single story structure.

Table 1. The physical and mechanical properties of soil-structure model.

\begin{tabular}{ccccc}
\hline Material Properties & Structure & Foundation & $\begin{array}{c}\text { Stiff clay } \\
\text { (Class D) }\end{array}$ & $\begin{array}{c}\text { Hard rock } \\
\text { (Class A) }\end{array}$ \\
\hline Mod. of elasticity (Pa) & $3 \times 10^{10}$ & $3 \times 10^{10}$ & - & - \\
Shear modulus (Pa) & - & - & $6 \times 10^{7}$ & $2.52 \times 10^{10}$ \\
Mass density (kg/m $\left.{ }^{3}\right)$ & 2550 & 2550 & 1500 & 2800 \\
$\quad$ Poisson's ratio & 0.20 & 0.20 & 0.33 & 0.33 \\
Wave amplitude, $2 \mathrm{~A}_{0}$ & - & - & 2.00 & 0.071 \\
$\begin{array}{c}\text { (cm) } \\
\text { Shear wave velocity, } \\
\text { vs (m/sec) }\end{array}$ & - & - & 200 & 3000 \\
\hline
\end{tabular}

\subsection{Equivalent SDOF model for the soil-structure system}

The equivalent SDOF model [30] is based on the idealization of the SSI by the rotational and the translational mass-springdashpots attached to the structure at the effective height
(Figure 3). In the SDOF model, $k, k_{h}$, and $k_{r}$ are the lateral stiffness coefficient of the structure, the lateral and the rotational static-stiffness coefficients for a rigid circular base mat, respectively. The frequencies corresponding to those are calculated as:

$$
\begin{gathered}
\omega_{s}^{2}=\frac{k}{m} \\
\omega_{h}^{2}=\frac{k_{h}}{m} \\
\omega_{r}^{2}=\frac{k_{r}}{m h^{2}}
\end{gathered}
$$

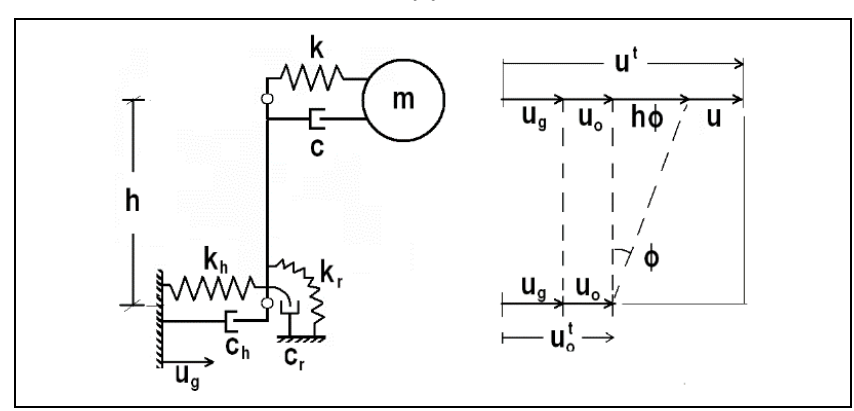

Figure 3. The single degree of freedom model for SSI [30].

Where $m$ and $h$ are the effective mass and height of the structure. In Figure $3, u_{0}, u_{g}, u$ and $\varphi$ denote the displacement amplitudes of the foundation, the ground motion and the mass due to the elastic deformation of the system and the rocking component of the mass, respectively. The structural damping coefficient $c$, lateral damping coefficient of the foundation $c_{h}$ (lateral) and $c_{r}$ (rotational) are zero for an undamped SDOF system. The coupled frequency of the SDOF model, $\omega$ is obtained as:

$$
\frac{1}{\omega^{2}}=\frac{1}{\omega_{s}^{2}}+\frac{1}{\omega_{h}^{2}}+\frac{1}{\omega_{r}^{2}}
$$

Where $\omega_{s}$ is the fixed based frequency of the structural mass, $\omega_{h}$ and $\omega_{r}$ are the natural frequencies of the mass with horizontal and rocking vibrations, respectively.

\subsection{The coupled frequency recommended by FEMA 450}

The provisions (FEMA 450) define the effective period of the building (the period of the coupled system), as below [29]:

$$
\bar{T}=T \sqrt{1+\frac{\bar{k}}{K_{y}}\left(1+\frac{K_{y} \bar{h}^{2}}{K_{\theta}}\right)}
$$

Where $T, \bar{k}$ and $\bar{h}$ are the fundamental period, the stiffness and effective height of the fixed based structure, respectively. The foundation is idealized as a rigid mat and the structure responds in its fixed based fundamental mode [31]-[33]. For mat foundations resting on elastic half space, $K_{y}$ and $K_{\theta}$ are the lateral and rocking stiffness values of the foundation as:

$$
\begin{gathered}
K_{y}=\frac{8 G r}{2-\mu} \\
K_{\theta}=\frac{8 G r^{3}}{3(1-\mu)}
\end{gathered}
$$

where $r$ is the radius of the foundation; $G$ and $\mu$ are the shear modulus and the Poisson's ratio of the soil. 


\subsection{The coupled frequency of the single story frame system}

One of the major effects of SSI is the shift in the fundamental frequency of the structure. The natural frequency of the fixed based structure is reduced particularly for the soft soil conditions. Therefore, the validation of the proposed procedure is discussed though the dynamic analysis of the single story frame resting on the stiff soil with the details given in Table 1. The fixed-base natural frequency of the structure is found to be $10.46 \mathrm{~Hz}$. It was observed that the fundamental frequency was reduced from $10.46 \mathrm{~Hz}$ to $8.65 \mathrm{~Hz}$ due to the effect of SSI in the current study. The shifted frequency is generally denoted as the coupled frequency of the soil-structure system in the literature. The coupled frequencies obtained by the proposed method are compared with the equivalent models given in Eqs. (22) and (23). The results of the current study are in good agreement with the existing models and they clearly reveal that the coupled frequency of the system is substantially reduced for each solution due to the effect of SSI for the stiff clay soil condition. The coupled frequency Eq. (23) recommended by FEMA 450 [29] regarding effect of soil structure interaction is the closest result to the exact solution obtained using the proposed method (Table 2).

Table 2. Comparison of the natural frequency of the soilstructure system.

\begin{tabular}{cccc}
\hline $\begin{array}{c}\text { Frequency of } \\
\text { soil-structure system }\end{array}$ & $\begin{array}{c}\text { Natural freq. } \\
\text { of fixed based } \\
\text { structure } \\
(\mathrm{Hz})\end{array}$ & $\begin{array}{c}\text { Freq. of } \\
\text { coupled } \\
\text { system } \\
(\mathrm{Hz})\end{array}$ & $\begin{array}{c}\text { Percent of } \\
\text { reduction } \\
(\%)\end{array}$ \\
\hline $\begin{array}{c}\text { Eq. (22) Equivalent } \\
\text { SDOF System [30] }\end{array}$ & 10.46 & 8.92 & 14.72 \\
$\begin{array}{c}\text { Eq (23) given in } \\
\text { FEMA 450 [29] }\end{array}$ & 10.46 & 8.60 & 17.78 \\
$\begin{array}{c}\text { 3D Modelling of the } \\
\text { Soil-Structure System } \\
\text { (This Study) }\end{array}$ & 10.46 & 8.65 & 17.30 \\
\hline
\end{tabular}

\section{Case 2: the numerical example-six story building}

The proposed numerical methodology is employed to obtain the displacement response and the IDR of a six-story residential building in the town of Düzce in the Northwestern part of Turkey (Figure 4). The reinforced concrete building has been constructed as moment resisting frame with plan dimensions of 19.4 and $20.4 \mathrm{~m}$. The building consists of columns and shear walls with varying dimensions located at the internal part of the building. Table 1 summarizes the physical and mechanical properties employed for the soil-structure model.

The 3D FE model of the building has been developed using ANSYS [24] based on the blue prints from the building survey conducted after Düzce Earthquake in 1999 (Figure 5) [34]. The raft foundation resting on stiff clay, which is the interface of the SSI has a thickness of $30 \mathrm{~cm}$ and is discretized by 30 rectangular elements. The natural frequencies obtained by the modal analysis of the fixed based structure and the proportional damping of each mode are given in Table 3.

In general, the analysis of the buildings including the rehabilitation process is conducted by linear elastic procedures with certain limitations given by the current seismic design codes. FEMA 356 [35] permits the use of linear elastic analysis of the buildings based on four conditions of structural irregularity. It can be clearly observed from the plan view of the building that the vertical structural members are almost symmetrically located on a regular orthogonal grid system (Figure 4). Since the multistory building analyzed in this study does not have any of the aforementioned structural irregularities stated in FEMA 356 [35], linear procedure has been used for the dynamic analysis of the structure.
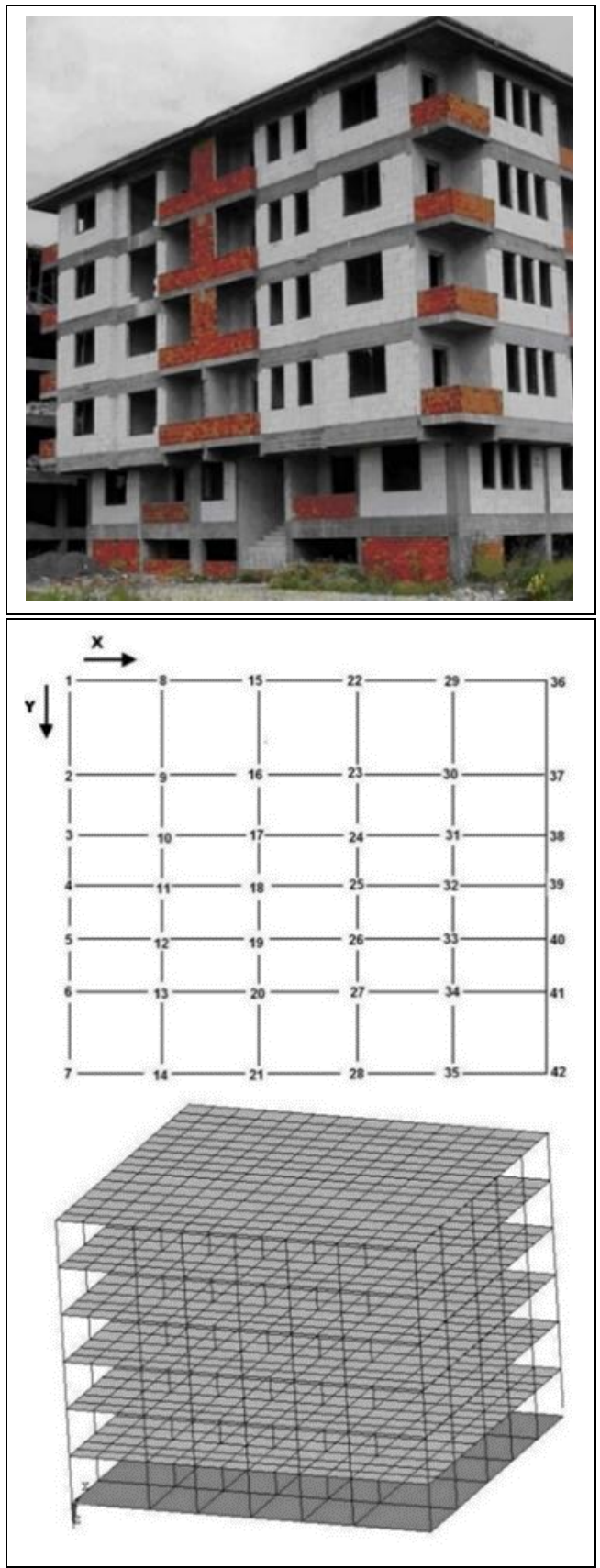

Figure 4. The multistory building in Düzce and 3D FEM of the building and foundation [34].

The analysis of the multistory reinforced concrete building is performed under the vertical and inclined SH and SV wave motions with the representative amplitudes regarding the impedance ratio of the soil types. The analysis of the existing building is performed for two types of soil conditions, Class D and Class A corresponding to stiff clay and hard rock as defined in FEMA 356 [35]. The impedance ratio of two soil types represents the soil amplification which is defined as: 


$$
\frac{A_{S 1}}{A_{S 2}}=\frac{\rho_{s 2} v_{s 2}}{\rho_{s 1} v_{s 1}}
$$

Where $A$ is the displacement amplitude, $\rho$ and $v_{s}$ are the mass density and shear wave velocity of the soil, respectively. In the numerical example, since $\left(\rho_{s} v_{s}\right)_{\text {rock }} /\left(\rho_{s} v_{s}\right)_{\text {soil }}$ is equal to 28, the displacement amplitude ratio of the waves, $\left(\mathrm{A}_{\text {rock }} / \mathrm{A}_{\text {soil }}\right)$ is accepted as $1 / 28$ in the analysis (Table 1 ). The drift demand at each story level has been estimated employing the displacement response of the soil-structure system.

Table 3. The natural frequencies and the damping ratio values.

\begin{tabular}{cccc}
\hline Mode & Frequency $(\mathrm{Hz})$ & Damping & Modes of vibration \\
\hline 1 & 1.70 & 0.05 & 1st mode in $\mathrm{x}$ - translation \\
2 & 2.13 & 0.05 & 1st mode in y - translation \\
3 & 2.24 & 0.05 & Torsional mode around z axis \\
4 & 5.92 & 0.09 & 2nd mode in $\mathrm{x}$ - translation \\
5 & 7.51 & 0.11 & 2nd mode in y - translation \\
6 & 7.87 & 0.11 & Torsional mode around z axis \\
7 & 11.97 & 0.16 & Translation in x direction \\
8 & 15.49 & 0.21 & Translation in y direction \\
9 & 16.12 & 0.22 & Translation in y direction \\
10 & 19.06 & 0.25 & Translation in z direction \\
\hline
\end{tabular}

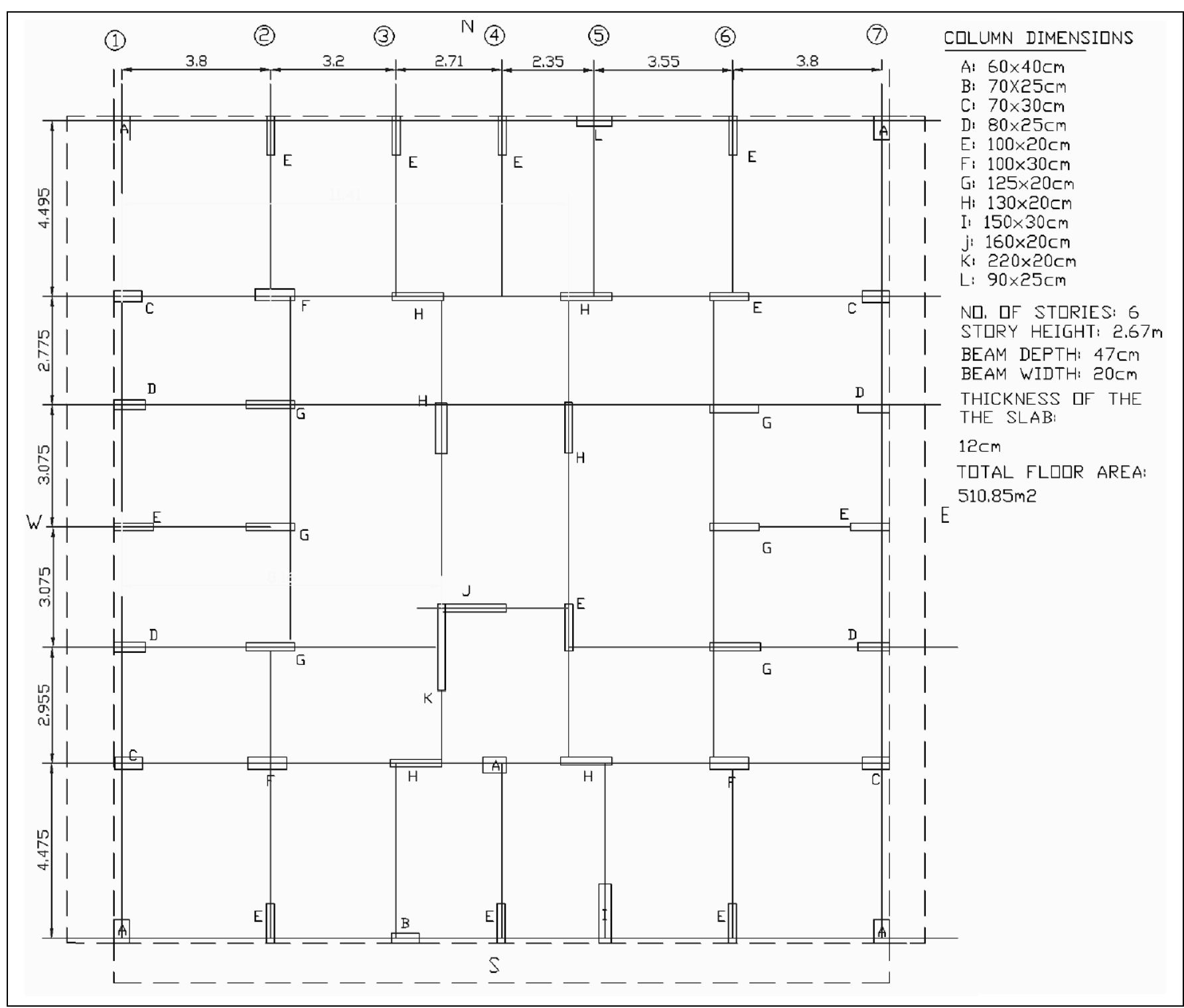

Figure 5. Plan view of the multistory building [34]. 


\section{SSI effect on the peak horizontal displacement of the building}

\subsection{The rocking motion of the building resting on the stiff clay}

The relative horizontal displacement response of the structure resting on rigid soil can be easily estimated by the difference of the total displacement and base motion. However, displacement response under the soft soil condition also includes rocking component which enforces the rigid body motion of the soil structure system (Figure 6a) reproduced from Wong et al. [36]. In this case, the total displacement, $u_{\mathrm{t}}(\mathrm{t})$ at any elevation of the building, $H_{\mathrm{N}}$ is composed of the translation and rocking components of the base $\left(u_{\mathrm{b}}(\mathrm{t})\right.$ and $u_{\mathrm{r}}(\mathrm{t})$, respectively); and the structural response, $u_{\mathrm{st}}(\mathrm{t})$ as;

$$
u_{\mathrm{t}}(\mathrm{t})=u_{\mathrm{b}}(\mathrm{t})+u_{\mathrm{r}}(\mathrm{t})+u_{\mathrm{st}}(\mathrm{t})
$$

Where $u_{\mathrm{r}}(\mathrm{t})=B . \alpha(t) ; B$ and $\alpha(t)$ refer to the foundation width and the rocking angle of the foundation. The structural response and the interstory drift ratio for the building resting on stiff clay are determined using Eq. (27) in the further sections. Figure $6 \mathrm{~b}$ shows the amplitude values of rocking angle of the foundation under vertical SH and SV wave motion and inclined SV wave motion.

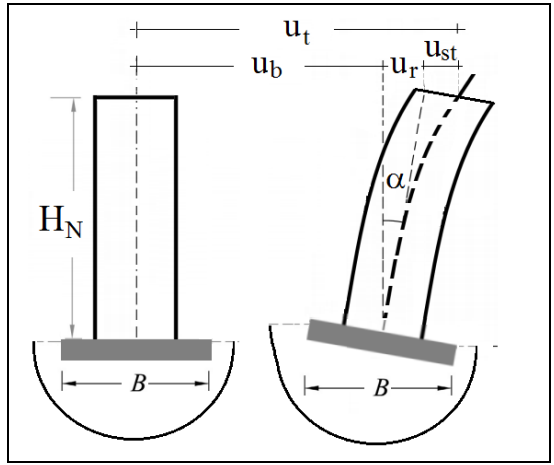

(a)

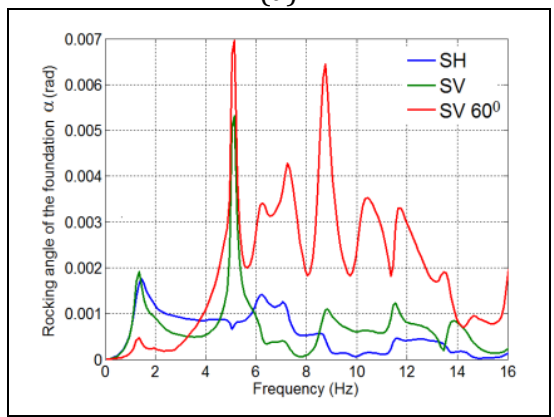

(b)

Figure 6. (a): Relative displacement response of the building considering rocking motion at the base. (b): Rocking angle of foundation resting on stiff clay under vertical SH and SV wave motion $\left(\theta_{v}=90^{\circ}\right)$ and inclined SV wave motion $\left(\theta_{v}=60^{\circ}\right)$.

The incident vertical SH and SV waves cause particle motion in $\mathrm{y}$ and $\mathrm{x}$ axes of the local coordinate system of the building, respectively. Thus, the amplitudes of the rocking component attain their peak values at the translational modes of vibration of the coupled system ( $\mathrm{f}=1.45 \mathrm{~Hz}$ and $1.35 \mathrm{~Hz}$ for SH and SV wave motions.) The maximum value of the rocking angle for the vertical SV wave motion is attained at a higher translational mode of the soil structure system in $\mathrm{x}$ direction at $\mathrm{f}=5.05 \mathrm{~Hz}$. However, the SSI has its highest effect on the dynamic response under the inclined SV wave motion due the rocking motion of the foundation resting on stiff clay.

\subsection{The response under vertical $S H$ and $S V$ wave motions $\left(\theta_{v}=9^{\circ}\right)$}

The solution of the wave equations for the vertical incidence reduces the problem to the elastic one dimensional wave motion for both SH and SV waves. For $\theta_{v}=90^{\circ}$, the free field displacement vectors at the interface are in phase inducing the identical excitation of the base nodes.

Using the elastic wave equations for the stress-free boundary condition on the surface of the soil $(\mathrm{z}=0)$, incident SH wave involves no particle motion perpendicular to the free field surface. Thus, the only non-zero component of the free field displacement vector, $\boldsymbol{u}_{f f}=\left\{\begin{array}{llllll}u_{f f} & v_{f f} & w_{f f}\end{array}\right\}^{T}$ is $v_{f f}$ which coincides with the y axis of the local coordinates of the building. For the vertical SH wave motion, the peak horizontal displacement amplitude for the building resting on hard rock (Class A) occurs at the fundamental mode of in y direction $(2.13$ $\mathrm{Hz}$ ). It is deduced that the coupled frequency of the soilstructure system on the stiff clay (Class D) has been reduced from $2.13 \mathrm{~Hz}$ to $1.45 \mathrm{~Hz}$ (Table 4). The relative displacement amplitudes at the top story resting on stiff clay (Class D) are significantly higher than those attained for the rigid soil (Class A) (Figure 7).

For the incident SV wave motion, the elastic wave equation for the same boundary conditions at $(\mathrm{z}=0)$ yields $u_{f f}$ and $w_{f f}$ components of the free field displacement vector, $\boldsymbol{u}_{f f}$ in $\mathrm{x}$ and $\mathrm{z}$ coordinates of the building. For the case under vertical SV wave motion $\left(\theta_{v}=90^{\circ}\right)$, vertical component of the free field displacement vector, $w_{f f}$ vanishes causing a particle motion in $\mathrm{x}$ direction due to $u_{f f}$ component. Thus, the response for the rigid soil condition (Class A) has its peak value at the fundamental mode in $\mathrm{x}$ direction $(1.75 \mathrm{~Hz}$ ) (Figure 7).

Similar to the incident vertical SH wave motion, the relative response of the case under soft soil condition (Class D) is higher than the structural response on rigid soil (Class A) at fundamental mode. However, the peak response of top story in $\mathrm{x}$ direction is attained at a higher mode of the structure $(20.77$ $\mathrm{cm}$ at $\mathrm{f}=5.05 \mathrm{~Hz}$ ) indicating that there exists a significant interaction between the soft soil and the flexible foundation. At this peak response, the horizontal motion at base $(-9.08 \mathrm{~cm})$ and the top $(11.69 \mathrm{~cm})$ are in antiphase where there is a phase shift of $+\pi$ between these elevations. Another reason of the amplified response is the distortion of the foundation due to the high rocking angle of the foundation plane.

It can be deduced that maximum response of the building is significantly affected by the soil stiffness and the shear wave velocity at the fundamental frequency. SSI has a major effect on the natural frequency of the buildings; it is reduced under the seismic loads particularly for those resting on soft soils. The reduction is higher for the buildings resting on soft soil however, the change in the natural frequency might be neglected for the structures built of rigid soil. Moreover, the stiff clay underlying the building enforces a rigid body motion of the structure and the foundation. The rocking motion of the foundation significantly increases the total displacement response for the case under soft soil conditions. 
The increase in drift values of the six story building resting on stiff clay was assessed under the vertical SH wave motion considering the response at the fundamental mode of the soilstructure system in y direction. In a previous study, the response of soil structure systems for a wide range of soft soil conditions were analyzed through modelling 2D frames with varying heights, including the plastic behavior of soil medium [37]. Direct Method was employed for analyzing the soilstructure system and the drift values were obtained through the exact incremental dynamic analysis under the action of thirty earthquake records. Similar to the drift results obtained in current study, for the medium clay, the average drift values were found to increase when compared with the fixed based models. The drift lengthening due to SSI was stated to be

(a) considerably higher for low and medium rise buildings than for the high rise buildings. In another study, drift lengthening due to SSI was investigated through 3D modelling of four different structures resting on three types of soils with Direct Method [38]. The dynamic analysis was conducted by linear elastic time history analysis under various earthquake records. It was found that, for low and midrise buildings (between three and seven stories) resting on soil with shear wave velocity lower than $375 \mathrm{~m} / \mathrm{s}$, the effect of SSI was most profound.

Table 5. demonstrates a general comparison between the previous studies and the current study in terms of the extent of increase in lateral drift for the multistory RC frames due to SSI.

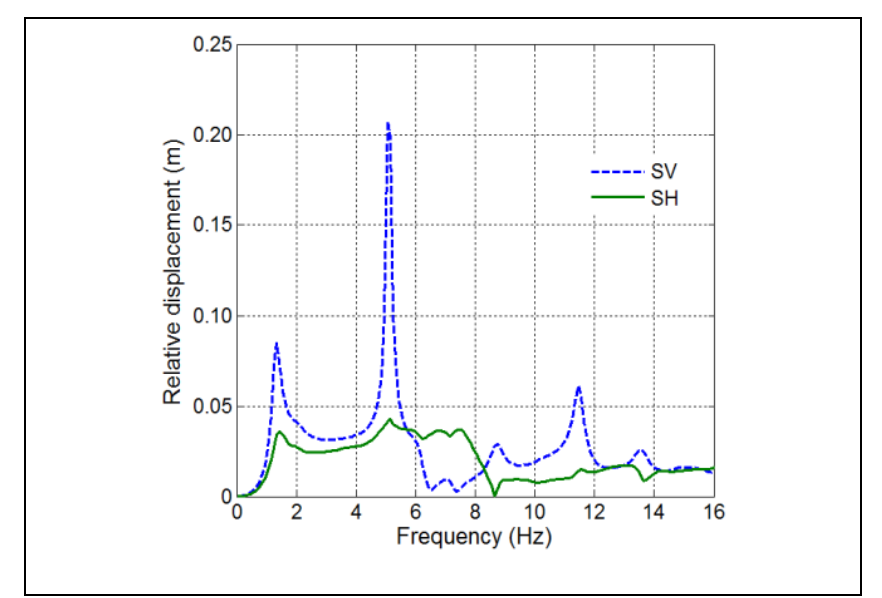

Figure 7. (a): Relative displacement response amplitude at the sixth story for the structure resting on stiff clay. (b): Hard rock under vertical wave motion.

Table 4. Lateral peak response of the building.

\begin{tabular}{|c|c|c|c|c|c|}
\hline \multirow{3}{*}{$\begin{array}{l}\text { Soil type } \\
\text { Wave type }\end{array}$} & \multicolumn{3}{|c|}{ Stiff clay (Class D) } & \multicolumn{2}{|c|}{ Hard rock (Class A) } \\
\hline & SH (y dir.) & SV (x dir.) & SV (x dir.) & SH (y dir.) & SV(x dir.) \\
\hline & ( $1^{\text {st }}$ mode $)$ & $\left(1^{\text {st }}\right.$ mode $)$ & (2nd mode) & $\left(1^{\text {st }}\right.$ mode $)$ & ( $1^{\text {st }}$ mode $)$ \\
\hline $\begin{array}{l}\text { Peak displacement response } \\
\text { amplitude at the base }\end{array}$ & $2.41 \mathrm{~cm}(1.45 \mathrm{~Hz})$ & $2.14 \mathrm{~cm}(1.35 \mathrm{~Hz})$ & $\begin{array}{c}10.83 \mathrm{~cm}(5.05 \\
\mathrm{Hz})\end{array}$ & $0.07 \mathrm{~cm}(2.05 \mathrm{~Hz})$ & $\begin{array}{c}0.07 \mathrm{~cm}(1.65 \\
\mathrm{Hz})\end{array}$ \\
\hline $\begin{array}{l}\text { Rocking component of the } \\
\text { displacement response at top }\end{array}$ & $2.85 \mathrm{~cm}(1.45 \mathrm{~Hz})$ & $3.10 \mathrm{~cm}(1.35 \mathrm{~Hz})$ & $8.21 \mathrm{~cm}(5.05 \mathrm{~Hz})$ & - & - \\
\hline $\begin{array}{l}\text { Displacement response } \\
\text { amplitude at the } 6^{\text {th }} \text { story } \\
\text { relative to the base }\end{array}$ & $3.61 \mathrm{~cm}(1.45 \mathrm{~Hz})$ & $8.51 \mathrm{~cm}(1.35 \mathrm{~Hz})$ & $\begin{array}{c}20.77 \mathrm{~cm}(5.05 \\
\mathrm{Hz})\end{array}$ & $0.89 \mathrm{~cm}(2.13 \mathrm{~Hz})$ & $\begin{array}{c}0.81 \mathrm{~cm} \mathrm{(1.75} \\
\mathrm{Hz})\end{array}$ \\
\hline Comparison with previous st & \multicolumn{2}{|c|}{$\begin{array}{c}\text { Shear wave velocity for soil } \\
\text { types }\end{array}$} & \multicolumn{2}{|c|}{$\begin{array}{l}\text { Freq. of fixed based } \\
\text { structure }\end{array}$} & $\begin{array}{l}\text { gthening due to } \\
\text { SSI }\end{array}$ \\
\hline $\begin{array}{l}6 \text { Story 2D frame, plastic behavior of } \\
\text { soil, Direct Method [37] }\end{array}$ & \multicolumn{2}{|c|}{$180 \mathrm{~m} / \mathrm{s} \leq \mathrm{V}_{\mathrm{s}} \leq 290 \mathrm{~m} / \mathrm{s}$} & \multicolumn{2}{|l|}{$1.07 \mathrm{~Hz}$} & $117 \%$ \\
\hline \multicolumn{2}{|c|}{5 Story 3D frame, Direct Method [38] } & $=150 \mathrm{~m} / \mathrm{s}$ & \multicolumn{2}{|l|}{$1.87 \mathrm{~Hz}$} & $158 \%$ \\
\hline \multicolumn{2}{|c|}{7 Story 3D frame, Direct Method [38] } & $=150 \mathrm{~m} / \mathrm{s}$ & \multicolumn{2}{|l|}{$1.45 \mathrm{~Hz}$} & $190 \%$ \\
\hline \multicolumn{2}{|c|}{$\begin{array}{c}6 \text { Story 3D frame, Coupled FEM-BEM } \\
\text { (This Study) }\end{array}$} & $=200 \mathrm{~m} / \mathrm{s}$ & \multicolumn{2}{|l|}{$2.13 \mathrm{~Hz}$} & $288 \%$ \\
\hline
\end{tabular}


The soil-structure system analyzed in the current study fall within the range of soil types and the structural characteristics of the benchmark cases in the field of research. Even though the previous studies were conducted through dynamic analysis under various seismic records employing direct method, the results are in good agreement with this study. Observing the results obtained by Tabatabaiefar et al. [38], it is found that the lateral drift values for five to seven story buildings on soft soils (shear wave velocity between $150-290 \mathrm{~m} / \mathrm{s}$ ) were remarkably increased due to SSI, which is consistent with the results of the current study. Obviously, the effect of SSI on the drift lengthening was observed to be lower for the 2D frame numerical case compared to the elastic soil-structure models, since the nonlinear behavior of the soil medium was included in the dynamic analysis [37]. The drift lengthening obtained in this study was higher than the comparative studies, which might be attributed to the flexible foundation conditions at the soil structure interface nodes in the improved method. Hence, the proposed procedure can reliably be employed to determine the dynamic response of soil structure systems under wave propagation.

\subsection{The response under inclined SV wave motion $\left(\boldsymbol{\theta}_{v}=\mathbf{6 0}^{\circ}\right)$}

An important aspect of the free field displacement caused by SV waves is that the characterization of the particle motion for the angle of incidence $\theta_{v}<\theta_{c r}$ and $\theta_{v}>\theta_{c r}$ changes drastically. The horizontal displacement amplitude, $u_{f f}$ has its peak value at the critical angle of incidence $\theta_{c r}=60^{\circ}$ that is related with the soil's Poisson's ratio. Above the critical angle of incidence, SV wave is reflected as SV and $P$ waves. The incident $S V$ waves are more destructive than $\mathrm{SH}$ waves for the intermediate angles which occurs when the ground surface is a steep slope, and the amplification of SV waves are stated to be much higher than that of SH waves [39]-[40]. The reflections of the SV waves from the inclined surface of steep slopes are in the form of other wave types, such as Rayleigh surface waves [41]. Previous studies also indicate that the damage is more significant for the buildings resting on steep slopes, which is referred to as the amplification of the seismic waves due to the topographical features of the site [42].

Similar to the vertical wave propagation, the incident SV wave with an angle of $\theta_{c r}=60^{\circ}$ also excites the y-direction fundamental mode ( $\mathrm{f}=2.13 \mathrm{~Hz})$ with an amplified displacement amplitude (Figure 8). Comparing the horizontal displacement response, the peak amplitude for the inclined SV wave propagation at the critical angle $\theta_{c r}=60^{\circ}$ is significantly higher than that of the vertical SV wave for both types of soils.

\subsection{SSI effect on the interstory drift demand of the building}

Interstory drift ratio (IDR) estimated by the ratio of relative horizontal displacements of adjacent stories to the story height is a response parameter which is highly related with damage in buildings [2]. Iwan [7] introduced the drift spectrum to obtain the drift demand by a continuous shear beam model under a nondispersive damped wave motion in forwards and backwards direction along the beam. Alternatively, Miranda et al. [2] have developed the generalized interstory drift spectrum employing a continuous model that combines a flexural beam and a shear beam.
In this study, the drift demand obtained for the rigid and the soft soil is used to identify the performance level of the multistory building. Comparing with the research conducted by Iwan [7] and Miranda et al. [2], this study focuses on the estimation of the drift demand of a multistory building for varying soil conditions under vertical $\mathrm{SH}$ and $\mathrm{SV}$ wave propagation. Obtaining the peak horizontal displacement response of each story, the performance level of the building is determined by the IDR limits stated in the provisions of FEMA 356 [35].

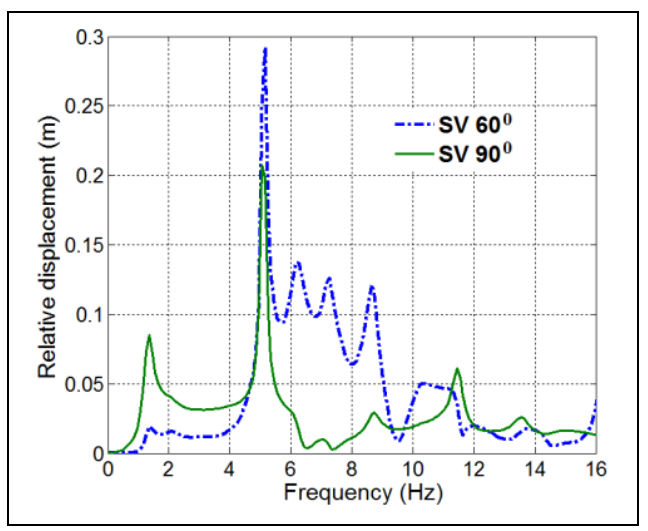

(a)

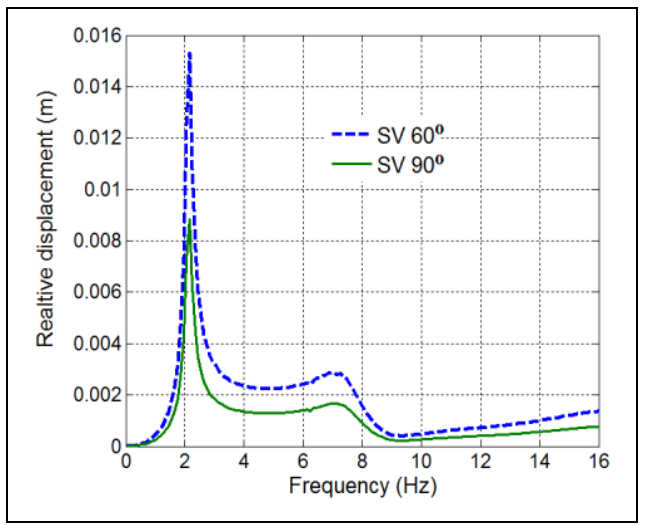

(b)

Figure 8. (a): Relative displacement response amplitude at the sixth story of the building resting on stiff clay and (b): Hard rock under vertical $\left(90^{\circ}\right)$ and inclined $\left(60^{\circ}\right) \mathrm{SV}$ wave motion.

\subsection{Lateral displacement response along the building height at the natural frequencies for fixed-based and coupled cases}

The relative displacement response curves for the structure resting on hard rock (Class A) correspond to the fundamental modes of the fixed based structure in its orthogonal directions (Figure 7). Since the vertical SH and SV wave propagations along the elastic halfspace invoke the fundamental modes of the structure in $\mathrm{y}$ direction $\left(\mathrm{f}_{y}=2.13 \mathrm{~Hz}\right)$ and $\mathrm{x}$ direction $\left(\mathrm{f}_{x}=1.73 \mathrm{~Hz}\right.$ ) respectively, the building exhibits its first mode of vibration in both directions. Similarly, the peak displacement response of the structure resting on stiff clay (Class D) occurs at the fundamental frequencies of the coupled systems ( $f_{\mathrm{y}-\text { reduced }}=1.45 \mathrm{~Hz}$ and $\mathrm{f}_{\mathrm{x} \text {-reduced }}=1.35 \mathrm{~Hz}$ ) where the structure deforms in its fundamental modes. The reduction in the fundamental frequencies is due to the underlying soil condition which is stiff clay. In Figure 9, the deformed shapes of building 
correspond to the first mode of vibration. Response at the coupled frequencies of the soil-structure systems shows that the lateral displacements of the system on soft soil are significantly higher than the results for the rigid soil.

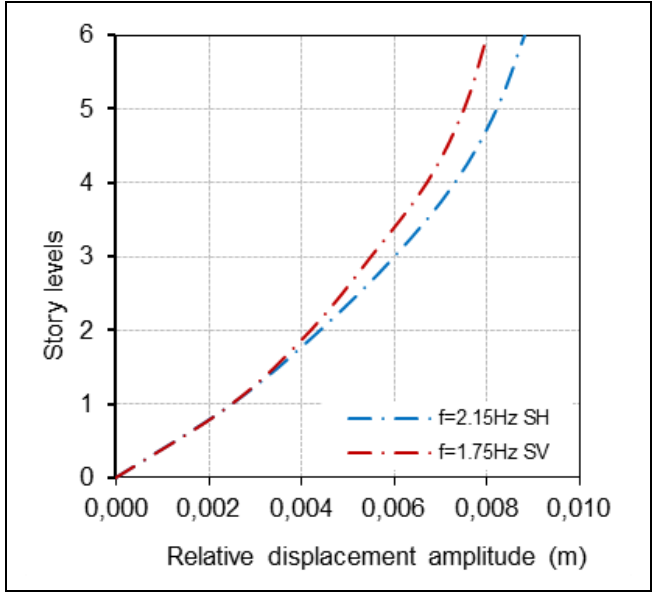

(a): Hard rock.

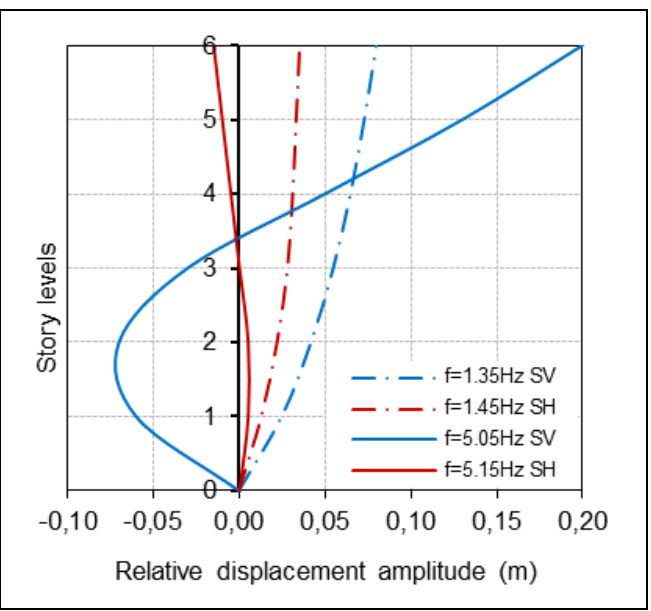

(b): Stiff clay.

Figure 9. Lateral displacement response at peak frequency of system along the building height for vertical SH and SV wave motions.

\subsection{IDR along the building height at fixed based frequency and coupled frequency of soil-structure system}

Figure 10 shows IDR along the height of the building at the peak response frequencies. For each case of analysis, maximum IDR occurs at the first story level also indicating the possible location of the structural damage. For the building resting on hard rock, IDR attains its maximum value of 0.0009 occurring at the first story at the fundamental frequency of building in each direction $\left(\mathrm{f}_{y}=2.13 \mathrm{~Hz}\right.$ and $\mathrm{f}_{x}=1.73 \mathrm{~Hz}$ ). Despite the fact that the distribution of IDR along the height of the building is similar for the soft soil condition (stiff clay), the drift demands in the orthogonal directions of the building are significantly higher due to the effect of SSI $(0.006$ and 0.011 in $y$ and $x$ directions). However, the maximum drift demand of the building (0.035) occurs at $\mathrm{f}=5.05 \mathrm{~Hz}$ for the building resting on stiff clay corresponding to a higher mode of the structure in $x$ direction. Thus, the location of the maximum IDR is the fifth story level at $5.05 \mathrm{~Hz}$ of excitation frequency.

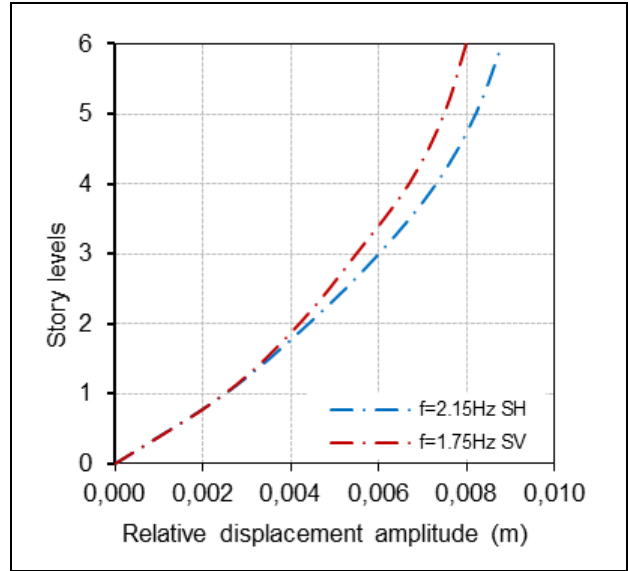

(a): Hard rock.

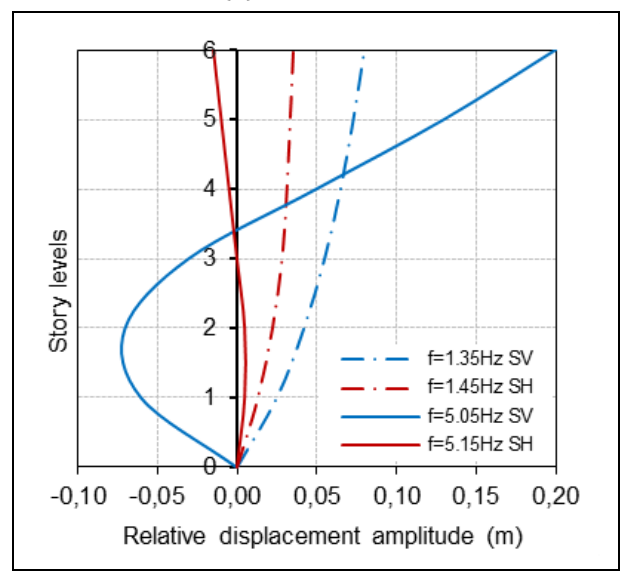

(b): Stiff clay.

Figure 10. IDR at the peak frequency of the system along the building height for vertical SH and SV wave motion.

\subsection{The maximum IDR spectrum of the multistory building under vertical SH and SV motion}

The drift demand of the structure under seismic motion is essentially related to the maximum values of IDR regardless of the location along the height of the building. Therefore, instead of estimating IDR for each story, it is more practical to define the drift demand in terms of the maximum IDR versus the excitation frequency, which consists of the peak values of IDR along the height of the building. It is also misleading to estimate the drift demand according to the first mode of vibration of the fixed based structure. Especially for the structure resting on stiff clay, the peak displacement response and the maximum IDR are attained at a higher frequency $(5.05 \mathrm{~Hz})$ in $\mathrm{x}$ direction. The interaction of the vibrational modes of the mat foundation and the structure as well as the rocking motion causes a significant amplification in the horizontal response for the soft soil case. Maximum IDR versus seismic wave frequency for the building resting on stiff clay and hard rock (Class D and Class A) are shown in Figure 11. For both soil conditions, the most critical part of the building is the first story except for the maximum IDR value of 0.033 which is obtained at the fifth story level under vertical SV motion at $5.05 \mathrm{~Hz}$ of excitation frequency in $\mathrm{x}$ direction of the building resting on stiff clay. Therefore, the plot of maximum IDR versus excitation frequency suggests a practical technique for the estimation of the drift demand and performance level of the multistory buildings under seismic wave motion. 


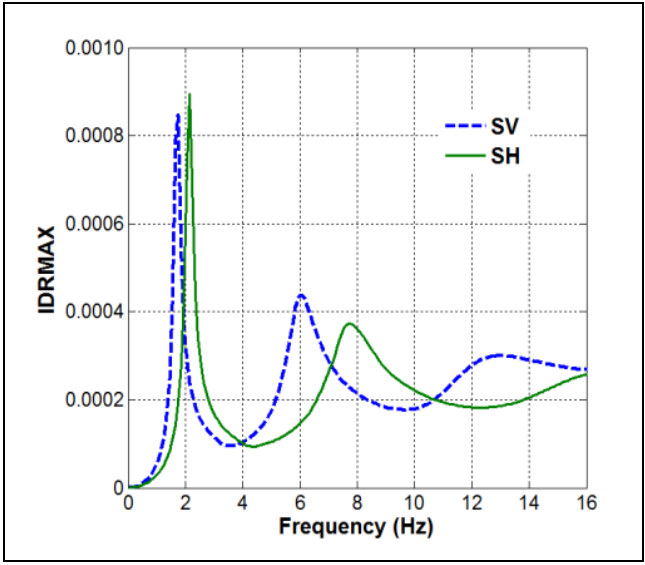

(a)

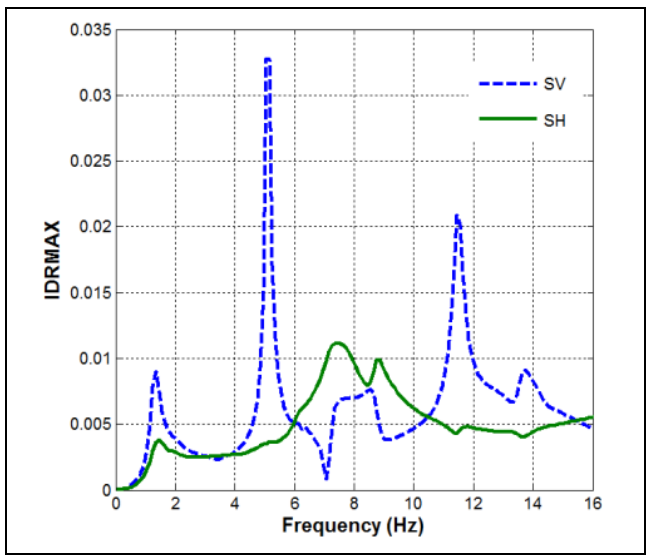

(b)

Figure 11(a): IDR for the building resting on stiff clay and

(b): Hard rock under vertical SH and SV wave motion.

\subsection{Maximum IDR as a design parameter for structures}

FEMA 356 [35] defines the drift limits for the concrete frames as Immediate Occupancy, Life Safety and Collapse Prevention and the ranges as Damage Control, Limited Safety and Not Considered (Table 6).

Table 6. Structural performance levels for concrete frames defined in FEMA 356 [35].

\begin{tabular}{cccc}
\hline \multicolumn{4}{c}{ Structural performance levels } \\
\hline Drift ratio & $\begin{array}{c}\text { Collapse } \\
\text { prevention }\end{array}$ & $\begin{array}{c}\text { Life } \\
\text { safety }\end{array}$ & $\begin{array}{c}\text { Immediate } \\
\text { occupancy }\end{array}$ \\
\hline Transient & 0.04 & 0.02 & 0.01 \\
Permanent & 0.04 & 0.01 & can be neglected \\
\hline
\end{tabular}

The maximum IDR of the soil-structure system resting on hard rock (Class A) is 0.0009 corresponding to the fixed-based natural frequency of the building $\left(\mathrm{f}_{y}=2.13 \mathrm{~Hz}\right)$. This value is quite below the Life Safety drift limit. However, the dynamic analysis of the building which is built on stiff clay (Class D) reveals that the IDR values at the coupled frequencies of the soil structure system are significantly higher than the results for fixed based analyses (0.011 and 0.006 in $\mathrm{x}$ and y directions). The maximum IDR value for the structure resting on stiff clay is attained at a higher mode of the soil-structure system $\left(\mathrm{f}_{x}=5.05 \mathrm{~Hz}\right.$ ) as 0.033 . This value corresponds to Limited Safety Range between Life Safety and Collapse Prevention levels of performance.

\section{Conclusion}

A six-story reinforced concrete building in Düzce is analyzed employing a coupled BEM-FEM technique developed for the analysis of the soil-structure systems under two extreme soil conditions as (i) hard rock (referring to the fixed based structure without SSI), and (ii) stiff clay (considering soilstructure interaction). The dynamic analyses are performed under vertical SH and SV wave propagations. The results obtained from the analyses are compared and discussed in terms of horizontal displacement response and interstorey drift ratio. Finally, the structural performance levels of the multistory building for each case are estimated according to maximum drift ratio values regarding the limiting values given by the seismic design codes.

Moreover, the soil structure system is analyzed for the inclined SV wave motion at the critical angle of incidence. The results show that the relative horizontal displacements of the structure as well as the free field displacement are much higher than the values obtained from the vertical SV wave propagation. Generally, the amplification of displacement due to the inclined SV wave motion occurs when the ground surface is a steep slope. Thus, the topographic features of the site strongly affect the seismic behavior of the structures leading to higher damage than the case for the buildings resting of horizontal ground surface. The comparison of the results for the two different soil conditions reveals that the increase in the relative horizontal displacement is more significant when the underlying soil is stiff clay. Moreover, the rocking component of the displacement response contributes a great deal to the total displacement of the soil structure system.

The seismic design and evaluation codes [35] define the performance levels in terms of IDR value which is practical structural parameter for the performance based design. The design of structures requires accurate estimation of the building deformations in order to satisfy the design performance level that has been determined according to the importance level of the building. Thus, there is a need for integrated design procedures including the seismic performance of the soil-structure system to ensure the estimated building performance level.

Especially for the structures resting on soft soils, the effect of SSI significantly increases the horizontal displacements and the drift demands. The increase in the displacement response may probably alter the building performance level as well. In this study, drift demands of the multistory building are obtained using the proposed technique for the dynamic analysis which provides an accurate and reliable method to estimate the drift values including the effect of soil underlying the structure.

According to the results for the case that the existing structure to be built on hard rock, the IDR is quite below Life Safety Level as defined in FEMA 356 [35]. However, the maximum IDR of the building resting on stiff clay falls into the Limited Safety Range. Therefore, the performance levels of a structure can significantly alter when the dynamic analysis is conducted considering the soil-structure interaction. Especially for the design of multistory buildings resting on soft soils, there is a need to improve the existing design procedures including the effects of SSI in order to obtain more reliable results representing the seismic behavior of the structures. 


\section{Author contribution statements}

Within the scope of this study, Ayşe Elif ÖZSOY ÖZBAY and Pelin GÜNDEŞ BAKIR contributed to the design and literature review of the research; to the interpretation of the results and to the preparation of the manuscript.

\section{Ethics committee approval and conflict of interest statement}

The authors declare that there is no conflict of interest with any person/institution in the article prepared.

\section{References}

[1] Akkar S, Yazgan U, Gülkan P. "Drift estimates in frame buildings subjected to near-fault ground motions". Journal of Structural Engineering, ASCE, 131(7), 1014-1024, 2005.

[2] Miranda E, Akkar S. "Generalized interstory drift demand spectrum", Journal of Structural Engineering, ASCE, 132(6), 840-852, 2006.

[3] Algan BB. Drift and Damage Considerations in Earthquake Resistant Design of Reinforced Concrete Buildings. $\mathrm{PhD}$ Thesis, University of Illinois at Urbana-Champaign, Urbana, Illinois, USA, 1982.

[4] Sozen MA. "Lateral drift of reinforced concrete structures subjected to strong ground motion". Bulletin of New Zealand National Society for Earthquake Engineering, 16(2), 107-122, 1983.

[5] Moehle JP. "Seismic drift and its role in design". Proceedings of $5^{\text {th }}$ US-Japan Workshop on the Improvement of Building Structural Design and Construction Practices, San Diego, USA, 8-10 September 1992.

[6] Bozorgnia Y, Bertero VV. "Improved shaking and damage parameters for post-earthquake applications". Proceedings of the SMIP01 Seminar on Utilization of StrongMotion Data, Los Angeles, California, USA, 12 September 2001.

[7] Iwan WD. "Drift spectrum: Measure of demand for earthquake ground motions" Journal of Structural Engineering, ASCE, 123(4), 397-404, 1997.

[8] Todorovska MI, Trifunac MD. "Structural health monitoring by detection of abrupt changes in response using wavelets: Application to a 6-story RC building damaged by an earthquake". Proceedings of $37^{\text {th }}$ Joint Panel Meeting on Wind and Seismic Effects, Tsukuba, Japan, 16-21 May 2005.

[9] Nguyen QV, Fatahi B, Hokmabadi AS. "The effects of foundation size on the seismic performance of buildings considering the soil-foundation-structure interaction". Structural Engineering and Mechanics, 58(6), 1045-1075, 2016.

[10] Liang J, Han B, Todorovska MI, Trifunac MD. "2D dynamic structure-soil-structure interaction for twin buildings in layered half-space I: Incident SH-waves". Soil Dynamics and Earthquake Engineering, 102, 172-194, 2017.

[11] Liang J, Han B, Todorovska MI, Trifunac MD. "2D dynamic structure-soil-structure interaction for twin buildings in layered half-space II: Incident SV-waves". Soil Dynamics and Earthquake Engineering, 113, 356-390, 2018.

[12] Lymser J, Udaka T, Tsai CF, Seed HB. "FLUSH - A Computer Program for Approximate 3D Analysis of Soil-Structure Interaction". University of California, Berkeley, California, USA, Report, EERC75-30, 1975.
[13] Velestos AS, Meek JW. "Dynamic behaviour of buildingfoundation systems". Earthquake Engineering and Structural Dynamics, 3(2), 121-138, 1975.

[14] Dominiguez J. "Response of Embedded Foundations to Travelling Waves". Department of Civil Engineering, Massachusetts Institute of Technology, Cambridge, MA, USA, Report, R78-24, 1978.

[15] Karabalis DL, Beskos DE. "Dynamic response of 3-D rigid surface foundations by time domain boundary element method". Earthquake Engineering and Structural Dynamics, 12, 73-93, 1984.

[16] Kausel E, Roesset J. "Stiffness matrices for layered soils". Bulletin of Seismological Society of America, 71(6), 1743-1761, 1981.

[17] Luco J, Apsel R. “On the Green's functions for a layered half-space" Part I". Bulletin of Seismological Society of America, 73(4), 909-929, 1983.

[18] Estorff OV, Kausel E. "Coupling of boundary and finite elements for soil-structure interaction problems". Earthquake Engineering and Structural Dynamics, 18, 1065-1075, 1989.

[19] Dendrou B. "A Methodology for the Dynamic Analysis of Bridge/Abutment/Backfill Systems Subjected to Traveling Seismic Waves". National Science Foundation, California, USA, Report, CEE-8007518, 1983.

[20] Cavalieri F, Correia AA, Crowley H, Pinho R. "Dynamic soilstructure interaction models for fragility characterisation of buildings with shallow foundations". Soil Dynamics and Earthquake Engineering, 2020. https://doi.org/10.1016/j.soildyn.2019.106004.

[21] Varghese R, Boominathan A, Banerjee S. "Stiffness and load sharing characteristics of piled raft foundations subjected to dynamic loads". Soil Dynamics and Earthquake Engineering, 2020. https://doi.org/10.1016/j.soildyn.2020.106117.

[22] Soyluk K, Sicacik EA. "Soil-Structure interaction analysis of cable-stayed bridges for spatially varying ground motion components". Soil Dynamics and Earthquake Engineering, $35,80-90,2012$.

[23] Ozsoy OEA, Dynamic Soil Structure Interaction under Wave Propagation via an Improved Coupled Finite Element-Boundary Element Methodology. PhD Thesis, Istanbul Technical University, İstanbul, Turkey, 2011.

[24] ANSYS Inc. "ANSYS Structural Release 14.5, References and Solver Notes". http://www.ansys.com (04.06.2013).

[25] Mathworks Inc. "MATLAB R2013" http://www.mathworks.de (13.02.2013).

[26] Ewing WM, Jardetsky WS, Press F. Elastic Waves in Layered Media. $1^{\text {st }}$ ed. New York, USA, McGraw-Hill, 1957.

[27] Lamb H. "On the propagation of tremors over the surface of an elastic solid". Philosophical Transactions of the Royal Society, 203, 1-42, 1904.

[28] Aki K, Richards PG. Quantitative Seismology, Theory and Methods, $1^{\text {st }}$ ed. San Francisco, USA, W.H. Freeman and Co. 1980.

[29] Federal Emergency Management Agency. "NEHRP Recommended Provisions for Seismic Regulations for New Buildings and Other Structures". Washington, DC, USA, FEMA450, 2004.

[30] Wolf JP. Dynamic Soil-Structure Interaction, $1^{\text {st }}$ ed. New Jersey, USA, Prentice-Hall, 1985.

[31] Jennings PC, Bielak J. "Dynamics of building-soil interaction". Bulletin of Seismology Society of America, 63(1), 9-48, 1973. 
[32] Luco JE. "Impedance functions for a rigid foundation on a layered medium". Nuclear Engineering and Design, 31, 204-217, 1974.

[33] Velestos AS, Meek JW. "Dynamic behaviour of buildingfoundation systems". Earthquake Engineering and Structural Dynamics, 3(2), 121-138, 1975.

[34] Purdue University. "A Curated Depository of Data on the Kocaeli-Gölcük and Düzce-Bolu Earthquakes of 1999". http://www.anatolianquake.org/ (14.11.2013).

[35] Federal Emergency Management Agency. "Prestandard and Commentary for the Seismic Rehabilitation of Buildings". Washington, DC, USA, FEMA356, 2000.

[36] Wong HL, Luco JE. "Effects of soil-structure interaction on the seismic response of structures subjected to active control". Proceedings of the $10^{\text {th }}$ Conference of Earthquake Engineering, Madrid, Spain, 19-24 July 1992.

[37] Zafarkhah E, Dehkordi MR. "Evaluation and numerical simulation of soil type effects on seismic soil-structure interaction response of RC structures". Journal of Vibroengineering, 19(7), 5208-5230, 2017.

[38] Tabatabaiefar, HR, Massumi A. "A simplified method to determine seismic responses of reinforced concrete moment resisting building frames under influence of soil structure interaction". Soil Dynamics and Earthquake Engineering, 30(11), 1259-1267, 2010.

[39] Assimaki D, Kausel E, Gazetas G. "Soil-dependent topographic effects: A case study from the 1999 Athens earthquake". Earthquake Spectra, 21(4), 929-966, 2005.

[40] Nazari A, Baziar MH, Shahnazari H. "Seismic Effects of Two-Dimensional Semi-Sine Shaped Hills on Ground Motion Response". Electronic Journal of Geotechnical Engineering, 15, 1159-1170, 2010.

[41] Jafarzadeh F, Shahrabi MM, Jahromi HF. "On the role of topographic amplification in seismic slope instabilities". Journal of Rock Mechanics and Geotechnical Engineering, 7(2), 163-170, 2015.

[42] Bouckovalas GD, Papadimitriou AG. "Numerical evaluation of slope topography effects on seismic ground motion". Soil Dynamics and Earthquake Engineering, 25, 547-558, 2005.

\section{Appendix A}

$$
\begin{array}{r}
f_{r r}\left(a_{0}\right)=\frac{a_{0}}{4 \pi}\left[\int_{0}^{\infty} \frac{z \sqrt{z^{2}-1}\left\{J_{2}\left(a_{0} z\right)-J_{0}\left(a_{0} z\right)\right\} d z}{F(z)}\right. \\
+\int_{0}^{\infty} \frac{z}{\sqrt{z^{2}-1}}\left\{J_{2}\left(a_{0} z\right)\right. \\
\left.\left.-J_{0}\left(a_{0} z\right)\right\} d z\right] \\
f_{\theta r}\left(a_{0}\right)=\frac{a_{0}}{4 \pi}\left[\int_{0}^{\infty} \frac{z \sqrt{z^{2}-1}\left\{J_{2}\left(a_{0} z\right)+J_{0}\left(a_{0} z\right)\right\} d z}{F(z)}\right. \\
+\int_{0}^{\infty} \frac{z}{\sqrt{z^{2}-1}}\left\{J_{2}\left(a_{0} z\right)\right. \\
\left.\left.-J_{0}\left(a_{0} z\right)\right\} d z\right] \\
f_{z z}\left(a_{0}\right)=-\frac{a_{0}}{4 \pi}\left[\int_{0}^{\infty} \frac{z \sqrt{z^{2}-n^{2}} \cdot J_{0}\left(a_{0} z\right) d z}{F(z)}\right] \\
f_{\theta z}\left(a_{0}\right)=0
\end{array}
$$

Rayleigh determinant $F(z)$ is determined as;

$$
\begin{gathered}
\mathrm{F}(\mathrm{z})=\left(2 z^{2}-1\right)^{2}-4 z^{2} \sqrt{\left(z^{2}-n^{2}\right)\left(z^{2}-1\right)} \\
\mathrm{n}=\frac{v_{S}}{v_{P}}=\sqrt{\frac{1-2 v}{2(1-v)}}
\end{gathered}
$$

The dimensionless frequency:

$$
a_{0}=\frac{\omega R}{v_{S}}
$$

